\title{
APPROKSIMASI LIMIT CYCLE PADA PERSAMAAN VAN DER POL DAN DUFFING TERIKAT
}

\author{
RATI FEBRIANTI, MAHDHIVAN SYAFWAN, EFENDI \\ Program Studi Matematika, \\ Fakultas Matematika dan Ilmu Pengetahuan Alam, Universitas Andalas, \\ Kampus UNAND Limau Manis Padang, Indonesia. \\ ratifebrianti27@gmail.com
}

\begin{abstract}
Abstrak. Pada artikel ini dikaji aproksimasi limit cycle pada persamaan van der Pol dan Duffing terikat. Limit cycle adalah lintasan tutup pada bidang fasa suatu persamaan diferensial nonlinier. Aproksimasi limit cycle ini diselesaikan dengan metode multiple scales. Perbandingan aproksimasi analitik dengan solusi numerik, yang diselesaikan dengan menggunakan metode Runge-Kutta orde 4, untuk parameter-parameter tertentu menunjukkan kesesuaian yang sangat baik untuk parameter pertubasi yang bernilai kecil.
\end{abstract}

Kata Kunci: Limit cycle, persamaan van der Pol, persamaan Duffing, multiple scales, metode Runge-Kutta orde 4

\section{Pendahuluan}

Sistem persamaan van der Pol dan Duffing terikat diberikan oleh [5]:

$$
\begin{aligned}
x^{\prime \prime}+\omega_{1}^{2} x+\mu_{1}\left(1-x^{2}\right) x^{\prime}+f y^{\prime \prime} & =0, \\
y^{\prime \prime}+\omega_{2}^{2} y+\mu_{2} y^{\prime}+c y^{3}-d x & =0,
\end{aligned}
$$

dimana $x, y$ adalah suatu fungsi yang bergantung pada waktu $t, \omega_{1}$ dan $\omega_{2}$ menunjukkan frekuensi bagi masing-masing persamaan, $\mu_{1}$ merupakan konstanta redaman sekaligus kenonlinieran bagi persamaan van der Pol, $\mu_{2}$ dan $c$ masing-masing menyatakan konstanta redaman dan kenonlinieran bagi persamaan Duffing, dan $f$ dan $d$ merupakan konstanta pengikat.

Persamaan (1.1 - 1.2) pertama kali dimodelkan oleh Chedjou dkk untuk menjelaskan transducer elektromekanik yang self-sustained yang terdiri dari bagian elektrik dan bagian mekanik yang terikat oleh gaya Laplace dan tegangan elektromotif Lenz [5]. Jika parameter $f=d=0$, maka persamaan (1.1) dan (1.2) masing-masing menjadi persamaan van der Pol dan persamaan Duffing teredam.

Persamaan van der Pol dan Duffing merupakan dua persamaan diferensial nonlinier orde 2. Persamaan van der Pol pertama kali diperkenalkan oleh seorang insinyur listrik dan fisikawan asal Belanda, Balthasar Van Der Pol, pada tahun 1927 [8]. Sedangkan persamaan Duffing diperkenalkan pertama kali oleh George Duffing pada tahun 1918 [9]. Kedua persamaan tersebut mendeskripsikan pergerakan osilator (seperti pendulum atau pegas) yang mengalami redaman. 
Pada artikel ini, persamaan van der Pol dan Duffing terikat diasumsikan berada dalam keadaan resonansi, yaitu $\omega_{1}=\omega_{2}=\omega$. Kemudian juga diasumsikan konstanta redaman, kenonlinieran dan pengikat bernilai kecil. Dari asumsi-asumsi tersebut, persamaan van der Pol dan Duffing terikat menjadi

$$
\begin{aligned}
x^{\prime \prime}+\omega^{2} x+\varepsilon \mu_{1}\left(1-x^{2}\right) x^{\prime}+\varepsilon f y^{\prime \prime} & =0, \\
y^{\prime \prime}+\omega^{2} y+\varepsilon \mu_{2} y^{\prime}+\varepsilon c y^{3}-\varepsilon d x & =0,
\end{aligned}
$$

dimana $\varepsilon \ll 1$.

Pada artikel ini akan dibahas aproksimasi limit cycle pada persamaan van der Pol dan Duffing terikat dimana konstanta redaman, kenonlinieran, dan pengikatnya bernilai kecil. Pada kasus ini, aproksimasi limit cycle tidak dapat lagi dilakukan dengan menggunakan metode pertubasi biasa (skala satu variabel) karena akan menghasilkan suku-suku sekuler. Untuk mengatasi hal tersebut, digunakan metode multiple scales. Kajian pada tugas akhir ini merupakan studi eksplorasi terhadap referensi [5].

Penulisan pada artikel ini disusun dengan sistematika sebagai berikut. Pada Bagian II dijelaskan solusi periodik dan limit cycle. Pada Bagian III dijelaskan ide dasar metode multiple scales. Kemudian pada Bagian IV dibahas formulasi analitik dari limit cycle. Selanjutnya, perbandingan aproksimasi analitik dengan solusi numerik dibahas pada Bagian V. Terakhir pada Bagian VI disajikan kesimpulan dan saran untuk studi berikutnya.

\section{Solusi Periodik dan limit cycle}

Solusi tak konstan dari suatu persamaan diferensial, katakanlah $x(t)$, disebut solusi periodik jika terdapat sebuah bilangan positif $T_{p}$ (disebut periode) sedemikian sehingga $x\left(t+T_{p}\right)=x(t)$ untuk semua $t$ [1]. Potret fase (yaitu himpunan representatif dari solusi yang diplot sebagai kurva parametrik) dari solusi periodik merupakan suatu lintasan tutup. Solusi periodik memiliki peranan penting dalam masalah-masalah fisis karena mereka merepresentasikan fenomena yang terjadi secara berulang, seperti detak jantung manusia, osilasi bandul, arus listrik AC, dan lain-lain.

Lebih lanjut, solusi periodik yang muncul dari suatu persamaan diferensial nonlinier dikenal dengan istilah limit cycle. Secara persis, limit cycle didefinisikan sebagai lintasan tutup pada bidang fasa suatu persamaan diferensial nonlinier sedemikian sehingga lintasan tak-tutup yang lain secara spiral menuju ke (atau keluar dari) lintasan tutup tersebut, baik dari dalam maupun dari luar, bilamana $t \rightarrow \infty$ (atau $t \rightarrow-\infty)[1]$.

Untuk lebih jelas, pada Gambar 2 diperlihatkan ilustrasi limit cycle pada bidang fasa suatu persamaan diferensial nonlinier.

\section{Metode Multiple Scales: Ide Dasar}

Perhatikan persamaan diferensial orde dua berikut [6].

$$
y^{\prime \prime}(t)+2 \varepsilon y^{\prime}(t)+y(t)=0, \quad t \geq 0, \varepsilon \ll 1,
$$




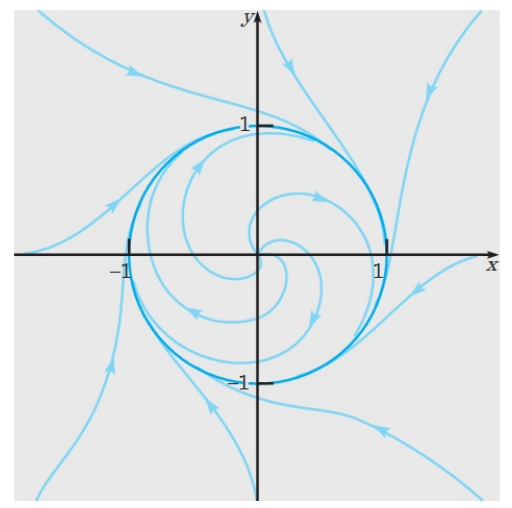

Gambar 1. [1] Ilustrasi limit cycle pada bidang fasa suatu persamaan diferensial nonlinier

dengan syarat awal

$$
y(0)=1, y^{\prime}(0)=0 .
$$

Misalkan solusi asimtotik dari persamaan (3.1) berbentuk

$$
y=y_{0}(t)+\varepsilon y_{1}(t)+O\left(\varepsilon^{2}\right) .
$$

Pada $O(1)$ solusi yang diperoleh adalah $y_{0}=\cos (t)$. Selanjutnya pada $O(\varepsilon)$ solusi yang diperoleh adalah $y_{1}=-t \cos (t)+\sin (t)$. Dengan demikian solusi asimtotik diberikan oleh

$$
y=\cos (t)+\varepsilon(-t \cos (t)+\sin (t))+O\left(\varepsilon^{2}\right), \varepsilon \ll 1 .
$$

Ketika $t \rightarrow \infty$, perbandingan antara suku kedua dengan suku pertama pada solusi di atas asimtotik ke $\varepsilon$, yang berarti tidak lagi bernilai kecil ketika $t=O\left(\varepsilon^{-1}\right)$. Jadi dapat disimpulkan bahwa solusi asimtotik (3.4) hanya valid untuk $t \ll \varepsilon^{-1}$. Untuk mengatasi permasalahan tersebut, definisikan variabel waktu baru yang 'lambat', $T=\varepsilon t$, sehingga ketika $t=O\left(\varepsilon^{-1}\right), T=O(1)$ dan prilaku solusi yang menurun secara lambat dapat di'tangkap'. Inilah yang menjadi ide dasar dari metode multiple scales. Jadi sekarang pandang solusi asimtotik yang berbentuk

$$
y=y_{0}(t, T)+\varepsilon y_{1}(t, T)+O\left(\varepsilon^{2}\right),
$$

dimana setiap suku adalah fungsi yang bergantung pada dua variabel waktu, yaitu $t$ untuk menjelaskan osilasi, dan $T$ untuk menjelaskan penurunan yang lambat.

\section{Formulasi Analitik}

Misalkan formulasi analitik dari limit cycle pada persamaan $(1.3-1.4)$ untuk $\varepsilon \ll 1$ dapat ditulis dalam bentuk ekspansi sebagai berikut:

$$
\begin{aligned}
& x=x_{0}(t, T)+\varepsilon x_{1}(t, T)+O\left(\varepsilon^{2}\right), \\
& y=y_{0}(t, T)+\varepsilon y_{1}(t, T)+O\left(\varepsilon^{2}\right),
\end{aligned}
$$

dimana $T=\varepsilon t$. 
Karena $x$ dan $y$ adalah fungsi-fungsi terhadap $t$ dan $T$, maka $x$ dan $y$ memenuhi persamaan diferensial parsial berikut ini:

$$
\begin{aligned}
\frac{d x}{d t} & =\frac{\partial x}{\partial t}+\varepsilon \frac{\partial x}{\partial T}, \\
\frac{d y}{d t} & =\frac{\partial y}{\partial t}+\varepsilon \frac{\partial y}{\partial T}, \\
\frac{d^{2} x}{d t^{2}} & =\frac{\partial^{2} x}{\partial t^{2}}+2 \varepsilon \frac{\partial^{2} t}{\partial t \partial T}+\varepsilon^{2} \frac{\partial^{2} x}{\partial T^{2}}, \\
\frac{d^{2} y}{d t^{2}} & =\frac{\partial^{2} y}{\partial t^{2}}+2 \varepsilon \frac{\partial^{2} y}{\partial t \partial T}+\varepsilon^{2} \frac{\partial^{2} y}{\partial T^{2}} .
\end{aligned}
$$

Selanjutnya substitusi persamaan $(4.3-4.5)$ ke persamaan $(1.3-1.4)$ dan gunakan ekspansi $(4.1-4.2)$, sehingga dapat dikumpulkan persamaan-persamaan orde berikut ini:

$$
\begin{aligned}
O(1): & \frac{\partial^{2} x_{0}(t, T)}{\partial t^{2}}+\omega^{2} x_{0}(t, T)=0 \\
& \frac{\partial^{2} y_{0}(t, T)}{\partial t^{2}}+\omega^{2} y_{0}(t, T)=0 \\
O(\varepsilon): & \frac{\partial^{2} x_{1}(t, T)}{\partial t^{2}}+\omega^{2} x_{1}(t, T)=-2 \frac{\partial^{2} x_{0}(t, T)}{\partial t \partial T}-\mu_{1}\left(1-x_{0}^{2}(t, T)\right) \frac{\partial x_{0}(t, T)}{\partial t} \\
& +f \omega^{2} \frac{\partial^{2} y_{0}(t, T)}{\partial t^{2}} \\
& \frac{\partial^{2} y_{1}(t, T)}{\partial t^{2}}+\omega^{2} y_{1}(t, T)=-2 \frac{\partial^{2} y_{0}(t, T)}{\partial t \partial T}-\mu_{2} \frac{\partial y_{0}(t, T)}{\partial t} \\
& -c y_{0}^{3}(t, T)+d x_{0}(t, T) .
\end{aligned}
$$

Solusi dari persamaan (4.6) dan (4.7) diberikan oleh

$$
\begin{aligned}
x_{0} & =A_{0}(T) \cos (\omega t)+B_{0}(T) \sin (\omega t), \\
y_{0} & =C_{0}(T) \cos (\omega t)+D_{0}(T) \sin (\omega t) .
\end{aligned}
$$

Dengan memisalkan $A_{0}(T)=A(T) \cos \left(\varphi_{1}(T)\right)$ dan $B_{0}(T)=B(T) \sin \left(\varphi_{2}(T)\right)$, persamaan (4.10) dan (4.11) berturut-turut ekuivalen dengan

$$
\begin{gathered}
x_{0}=A \cos \left(\omega t+\varphi_{1}\right), \\
y_{0}=B \cos \left(\omega t+\varphi_{2}\right) .
\end{gathered}
$$

Dengan mensubstitusikan persamaan (4.12) dan (4.13) ke dalam persamaan (4.8) dan (4.9), diperoleh

$$
\begin{aligned}
\frac{\partial^{2} x_{1}}{\partial t^{2}}+\omega^{2} x_{1}= & 2 \omega \frac{d A}{d T} \sin \left(\omega t+\varphi_{1}\right)-2 A \omega \frac{d \varphi_{1}}{d T} \cos \left(\omega t+\varphi_{1}\right) \\
& +\mu_{1} A \omega \sin \left(\omega t+\varphi_{1}\right)+\mu_{1} \omega A^{3} \cos ^{2}\left(\omega t+\varphi_{1}\right) \sin \left(\omega t+\varphi_{1}\right) \\
& +f \omega^{2} B \cos \left(\omega t+\varphi_{2}\right) \\
\frac{\partial^{2} y_{1}}{\partial t^{2}}+\omega^{2} y_{1}= & 2 \omega \frac{d B}{d T} \sin \left(\omega t+\varphi_{2}\right)-2 B \omega \frac{d \varphi_{2}}{d T} \cos \left(\omega t+\varphi_{2}\right) \\
& +\mu_{2} B \omega \sin \left(\omega t+\varphi_{2}\right)-c B^{3} \cos ^{3}\left(\omega t+\varphi_{2}\right) \\
& +d A \cos \left(\omega t+\varphi_{1}\right)
\end{aligned}
$$


Selanjutnya definisikan $v(T)=\varphi_{2}(T)-\varphi_{1}(T)$, sehingaa persamaan $(4.14-4.15)$ dapat ditulis ulang menjadi

$$
\begin{aligned}
\frac{\partial^{2} x_{1}}{\partial t^{2}}+\omega^{2} x_{1}= & \left(2 \frac{d A}{d T} \omega+\mu_{1} \omega A-\frac{\mu_{1} \omega A^{3}}{4}\right) \sin \left(\omega t+\varphi_{1}\right) \\
& -\frac{\mu_{1} \omega A^{3}}{4} \sin \left(3\left(\omega t+\varphi_{1}\right)\right)-2 A \omega \frac{d \varphi_{1}}{d T} \cos \left(\omega t+\varphi_{1}\right) \\
& +f \omega^{2} B \cos (v(T)) \cos \left(\omega t+\varphi_{1}\right) \\
& -f \omega^{2} B \sin (v(T)) \sin \left(\omega t+\varphi_{1}\right) \\
\frac{\partial^{2} y_{1}}{\partial t^{2}}+\omega^{2} y_{1}= & \left(2 \frac{d B}{d T} \omega+\mu_{2} B \omega\right) \sin \left(\omega t+\varphi_{2}\right) \\
& -\left(2 B \omega \frac{d \varphi_{2}}{d T}+\frac{3 c B^{3}}{4}\right) \cos \left(\omega t+\varphi_{2}\right) \\
& -\frac{c B^{3}}{4} \cos \left(3\left(\omega t+\varphi_{2}\right)\right) \\
& +d A \cos (v(T)) \cos \left(\omega t+\varphi_{2}\right) \\
& +d A \sin (v(T)) \sin \left(\omega t+\varphi_{2}\right)
\end{aligned}
$$

Karena versi homogen dari kedua persamaan $(4.16$ - 4.17) serupa dengan persamaan pada $O(1)$, maka solusi homogennya juga memuat suku $\cos \left(\omega t+\varphi_{1}\right)$ dan $\cos \left(\omega t+\varphi_{2}\right)$. Kemudian bagian nonhomogen juga mengandung suku-suku $\sin \left(\omega t+\varphi_{i}\right), \cos \left(\omega t+\varphi_{i}\right), i=1,2$, yang sama bentuknya dengan solusi homogen. Oleh karena itu solusi partikularnya akan memuat suku $t \sin \left(\omega t+\varphi_{i}\right)$ dan $t \cos \left(\omega t+\varphi_{i}\right), i=1,2$. Tetapi hal ini akan membuat ekspansi (4.1) dan (4.2) menjadi tidak valid (fenomena ini disebut nonuniformity). Suku-suku yang menyebabkan suatu ekspansi asimtotik nonuniform, disebut suku-suku sekuler. Agar ekspansi tersebut tetap uniform, maka suku-suku sekuler tersebut harus dieliminasi.

$$
\begin{aligned}
2 \frac{d A}{d T} \omega+\mu_{1} \omega A-\frac{1}{4} \mu_{1} \omega A^{3}-f \omega^{2} B \sin (v(T)) & =0, \\
\left(2 \frac{d B}{d T} \omega+\mu_{2} B \omega\right)+\frac{d A}{d T} \sin (v(T)) & =0, \\
-2 A \omega \frac{d \varphi_{1}}{d T}+f \omega^{2} B \cos (v(T)) & =0, \\
-2 B \omega \frac{\varphi_{2}}{d T}-\frac{3 c B^{3}}{4}+d A \cos (v(T)) & =0 .
\end{aligned}
$$

Perhatikan bahwa persamaan $(4.18-4.21)$ berturut-turut dapat ditulis kembali menjadi

$$
\begin{aligned}
\frac{d A}{d T} & =-\frac{1}{2} \mu_{1} A+\frac{1}{8} \mu_{1} A^{3}+\frac{1}{2 \omega} f \omega^{2} B \sin (v(T)), \\
\frac{d B}{d T} & =-\frac{1}{2} \mu_{2} B-\frac{1}{2 \omega} d A \sin (v(T)), \\
\frac{d v(T)}{d T} & =\left(\frac{d A}{2 \omega B}-\frac{\omega^{2} B f}{2 A \omega}\right) \cos (v(T))-\frac{3 c B^{2}}{8 \omega} .
\end{aligned}
$$

Karena limit cycle adalah solusi steady-state dari suatu sistem dinamik, maka 
104 Rati Febrianti dkk.

$\frac{d A}{d T}=\frac{d B}{d T}=\frac{d v}{d T}=0$. Dengan demikian persamaan (4.22), (4.23), dan (4.24) menjadi

$$
\begin{aligned}
& 0=-\frac{1}{2} \mu_{1} A+\frac{1}{8} \mu_{1} A^{3}+\frac{1}{2 \omega} f \omega^{2} B \sin (v(T)), \\
& 0=-\frac{1}{2} \mu_{2} B-\frac{1}{2 \omega} d A \sin (v(T)), \\
& 0=\left(\frac{d A}{2 \omega B}-\frac{\omega^{2} B f}{2 A \omega}\right) \cos \left((v(T))-\frac{3 c B^{2}}{8 \omega} .\right.
\end{aligned}
$$

Dengan mengeliminasi suku yang memuat $\sin (v(T))$ pada persamaan (4.25) dan (4.26), diperoleh

$$
\begin{aligned}
B^{2} & =\frac{-\mu_{1} A^{2} d \omega}{\mu_{2} \omega^{2} f}\left(\frac{A^{2}-4}{4}\right), \\
\frac{3 c B^{2}}{8 \omega} & =\left(\frac{d A}{2 \omega B}-\frac{\omega^{2} B f}{2 A \omega}\right) \sqrt{1-\left(\frac{\omega \mu_{2} B}{d A}\right)^{2}} .
\end{aligned}
$$

Dengan memperhatikan bentuk suku-suku nonhomogen yang bukan suku sekuler, maka solusi partikular untuk $x_{1}$ dan $y_{1}$ dapat ditulis

$$
\begin{aligned}
& x_{1 p}(t, T)=\frac{\mu_{1} A^{3}}{32 \omega} \sin \left(3\left(\omega t+\varphi_{1}\right)\right), \\
& y_{1 p}(t, T)=\frac{c B^{3}}{32 \omega^{2}} \cos \left(3\left(\omega t+\varphi_{2}\right)\right) .
\end{aligned}
$$

Secara keseluruhan, aproksimasi limit cycle dari persamaan (1.3) dan (1.4) dengan ketelitian sampai orde $\varepsilon^{2}$ diberikan oleh

$$
\begin{aligned}
& x(t, T)=A \cos \left(\omega t+\varphi_{1}\right)+\varepsilon \frac{\mu_{1} A^{3}}{32 \omega} \sin \left(3\left(\omega t+\varphi_{1}\right)\right), \\
& y(t, T)=B \cos \left(\omega t+\varphi_{2}\right)+\varepsilon \frac{c B^{3}}{32 \omega^{2}} \cos \left(3\left(\omega t+\varphi_{2}\right)\right),
\end{aligned}
$$

dimana $A$ dan $B$ adalah solusi dari sistem persamaan $(4.26-4.27)$.

\section{Perbandingan dengan Hasil Numerik}

Persamaan $(1.3-1.4)$ dapat ditulis dengan memisalkan $x^{\prime}(t)=p(t)$ dan $y^{\prime}(t)=q(t)$

$$
\begin{aligned}
& x^{\prime}=p, \\
& p^{\prime}=-\varepsilon \mu_{1}\left(1-x^{2}\right) p-(\omega+\varepsilon f d) x+\varepsilon f \omega^{2} y+\varepsilon f c y^{3}+\varepsilon f \mu_{2} q, \\
& y^{\prime}=q, \\
& q^{\prime}=-\varepsilon \mu_{2} q-\omega^{2} y-\varepsilon c y^{3}+\varepsilon d x .
\end{aligned}
$$

Untuk syarat awal, digunakan solusi eksak ketika $\varepsilon=0$, yaitu solusi leading order pada persamaan $(4.32-4.33)$. Karena $\varphi_{1}$ dan $\varphi_{2}$ pada kedua solusi tersebut hanya menunjukkan konstanta geseran, maka tanpa mengurangi keumuman, dapat dipilih $\varphi_{1}=0$ dan $\varphi_{2}=0$. Dengan demikian syarat awal untuk sistem (5.1) diberikan oleh

$$
x(0)=A, p(0)=\frac{3 \varepsilon \mu_{1} A^{3} \omega}{32 \omega}, y(0)=B+\frac{\varepsilon c B^{3}}{32 \omega^{2}}, q(0)=0 .
$$


Sebagai contoh ilustrasi, misalkan

$$
\mu_{1}=0.33, d=0.66, f=0.33, c=0.01, \omega=1.0 \operatorname{dan} \mu_{2}=0.7 .
$$

Selanjutnya untuk nilai-nilai parameter tersebut, solusi $A$ dan $B$ pada sistem persamaan (4.28) dan (4.29) dapat ditentukan dengan menggunakan aplikasi Maple 12, yaitu diperoleh $A=0.4781520480$ dan $B=0.4508256101$.

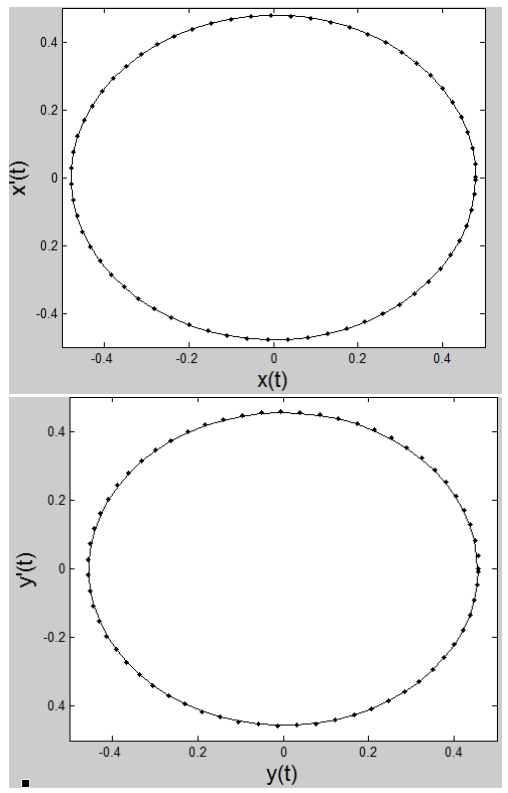

Gambar 2. Potret fasa limit cycle dari persamaan (1.3 - 1.4) yang diperoleh secara analitik (garis bulat) dan numerik (garis utuh) pada bidang- $\left(x(t), x^{\prime}(t)\right)$ dan bidang- $\left(y(t), y^{\prime}(t)\right)$ dengan $\varepsilon=0.001$.

Pada Gambar 2 ditunjukkan potret fasa limit cycle dari persamaan (1.1) dan (1.2) pada bidang- $\left(x(t), x^{\prime}(t)\right)$ dan $\left(y(t), y^{\prime}(t)\right)$ dengan menggunakan $\varepsilon=0.001$.

Pada Gambar 3 ditunjukkan potret fasa limit cycle untuk $\varepsilon=0.1$. Dari kedua gambar dapat dilihat bahwa aproksimasi analitik dan solusi numerik untuk nilai-nilai parameter pada (5.3) menunjukkan kesesuaian yang sangat baik antara keduanya. Lebih lanjut, aproksimasi limit cycle yang diperoleh dari metode multiple scales semakin baik hasilnya untuk $\varepsilon$ yang semakin kecil.

\section{Kesimpulan}

Berdasarkan uraian sebelumnya, dengan menggunakan metode multiple scales, diperoleh aproksimasi analitik untuk limit cycle dari persamaan $(1.3-1.4)$ sampai 


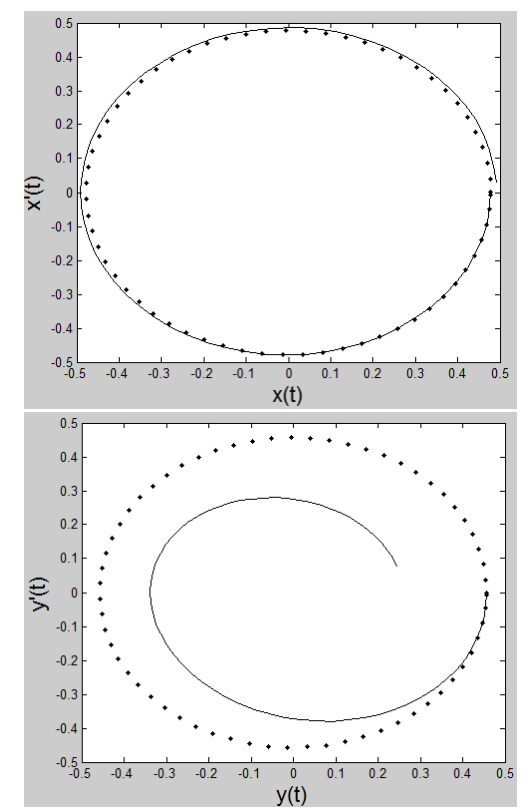

Gambar 3. Potret fasa limit cycle dari persamaan $(1.3-1.4)$ yang diperoleh secara analitik (garis bulat) dan numerik (garis utuh) pada bidang- $\left(x(t), x^{\prime}(t)\right)$ dan bidang- $\left(y(t), y^{\prime}(t)\right)$ dengan $\varepsilon=0.1$.

ketelitian orde $\varepsilon^{2}$, yang diberikan oleh

$$
\begin{aligned}
& x(t)=A \cos \left(\omega t+\varphi_{1}\right)+\varepsilon \frac{\mu_{1} A^{3}}{32 \omega} \sin \left(3\left(\omega t+\varphi_{1}\right)\right), \\
& y(t)=B \cos \left(\omega t+\varphi_{2}\right)+\varepsilon \frac{c B^{3}}{32 \omega^{2}} \cos \left(3\left(\omega t+\varphi_{2}\right)\right) .
\end{aligned}
$$

Aproksimasi analitik tersebut kemudian dibandingkan dengan solusi numerik yang diperoleh dengan menggunakan metode Runge-Kutta orde 4. Hasil perbandingan antara analitik dan numerik untuk nilai-nilai parameter tertentu menunjukkan kesesuaian yang sangat baik antara keduanya. Lebih lanjut, aproksimasi limit cycle yang diperoleh dari metode multiple scales ini semakin baik hasilnya untuk nilai $\varepsilon$ yang semakin kecil.

Untuk penelitian selanjutnya, penulis menyarankan untuk mengkaji bifurkasi Hopf yang muncul pada persamaan $(1.3-1.4)$ yang darinya dapat ditentukan daerah eksistensi (dalam ruang parameter) dari limit cycle.

\section{Ucapan Terima kasih}

Penulis mengucapkan terima kasih kepada Bapak Prof. Dr. Syafrizal Sy, Bapak Narwen, M.Si, dan Bapak Zulakmal, M.Si yang telah memberikan masukan dan saran dalam penyempurnaan penulisan artikel ini. 


\section{Daftar Pustaka}

[1] Boyce, William E dan Richard C. Diprima. (2009). Elementary Differential Equations and Boundary Value problems. Jhon Wiley and Son: New York.

[2] Chedjou J C, Woafo P, and Domngang S, (2001), "Shilnikov Chaos and Dynamics of A Self-Sustained Electromechanical Transducer", ASME J Vib Acous 123: $170-174$.

[3] Finizio, N dan G. Ladas. (1988).Persamaan Diferensial Biasa dengan Penerapan Modern. Erlangga: Jakarta.

[4] Iserles, A.. (2009). A First Course in the Numerical Analysis of Differential Equations. Cambridge University Press: Cambridge.

[5] Jianping Cai and Jianhe Shen, (2008), "Hopf Bifurcation analysis and approximation of Limit Cycle in Coupled Van Der Pol and Duffing Oscillators". The open Acoustics, Vol 1: 19 - 23.

[6] King, A.C, J. Bilingham, and S.R. Otto. (2003). Differential Equations: Linier, Ordinary, Partial. Cambridge University Press: Cambridge.

[7] Nayfeh, Ali Hasan. (1981). Introduction to Pertubation Techniques. Jhon Wiley and Sons: New York.

[8] http://en.wikipedia.org/wiki/Vanderpol.oscillator [diakses 20 November 2014]

[9] http://en.wikipedia.org/wiki/Duffing.equation [diakses 20 November 2014] 